\section{Summary of the Canadian Association of Gastroenterology 2004 Strategic Plan}

\author{
Ronald J Bridges MD FRCPC, President CAG \\ William G Paterson MD FRCPC, Past President CAG \\ Paul Sinclair MSc, Executive Director CAG \\ David G Morgan MD FRCPC, President-Elect CAG
}

Tn 2004, the Canadian Association of Gastroenterology 1 (CAG) developed a strategic plan (1) to build on the accomplishments of the preceding 42 years of work (2), and to guide the progress and development of the organization for the next five years. The CAG has traditionally promoted the advancement of the science and art of gastroenterology by supporting training and education at all levels, and by sustaining and engaging in the advancement of the study of digestive health sciences and diseases. The strategic plan was structured into five principal initiatives with associated specific goals and targets.

\section{PRINCIPAL INITIATIVES OF THE CAG 2004 STRATEGIC PLAN}

1. Emphasize the development of the next generation of gastroenterology clinical practitioners, researchers, educators and leaders.

2. Develop and support sustained local, provincial and federal governmental affairs and advocacy programs.

3. Promote and enhance professional alliances and vibrant provincial partnerships.

4. Support and enhance the scope of clinical practice, and educational and research programs.

5. Grow resources to provide additional and enhanced services to members of the CAG.

On behalf of the CAG Board, we are pleased to provide a report summarizing the activities and accomplishments of the organization related to the principal initiatives during the past five years.

\section{Principal Initiative 1}

Considerable work has been conducted through a variety of initiatives to emphasize the development of the next generation of digestive health care providers, researchers, educators and leaders. In response to reports of excessive patient wait times for care and concerns regarding the number of digestive health care specialists, the CAG launched a human resources planning project in 2004 that involved three complementary initiatives. The first was a detailed census of gastroenterology

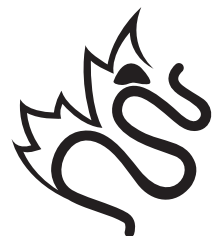

Canadian Association of Gastroenterology

En français voir page 170 human resources in Canada compared with other countries as well as a report of professionals providing digestive health care in Canada $(3,4)$. The second initiative was a multidisciplinary consensus panel charged with establishing evidence- and expertise-based target maximal wait times or benchmarks for digestive health care (5). The third initiative was a series of practice audits $(6,7)$, the Practice Audit in Gastroenterology (PAGE) (8) and the Survey of Access to GastroEnterology (SAGE) (9), that quantified actual wait times for digestive disease consultations and procedures. In 2007, the CAG was invited to join the Canadian Wait Time Alliance (WTA) for Timely Access to Health Care. National and provincial clinical endoscopy workforce resources were reported in a study published in 2007 (4). All of this information is critical to resource planning for quality digestive health care in the face of a growing and aging population, evolving standards of care and new technologies. A research needs assessment addressing the perceptions of stakeholders regarding relative investment in research was performed in 2009; the information is currently being analyzed. Significant progress related to resource planning has been made; however, further thought, planning and action are required to enable the effective use of the data acquired to approach national and provincial government training, funding and licensing bodies to advocate for appropriate numbers of health care specialists and researchers in the field of digestive health and disease.

Based on the current membership of the CAG, there appears to be broad representation of individuals from different cultural backgrounds and regions. The Gastroenterology Residents in Training (GRIT) and Scholars programs at Canadian Digestive Diseases Week (CDDW) have successfully raised the profile of gastroenterology among trainees and medical students, and high-quality candidates have been attracted into gastroenterology residency programs. The CAG supports a successful partnership program with the Canadian Institutes of Health Research (CIHR), the Crohn's and Colitis Foundation of Canada (CCFC), industry and the Canadian Digestive Health Foundation (CDHF) to train undergraduate, graduate and post-doctoral fellows, as well as provide operating grants to members. An annual topics course for research trainees, run in

The CAG is proud to acknowledge its Benefactor Corporate Sponsors:

Abbott Canada

AstraZeneca Canada Inc
Axcan Pharma Inc

Olympus Canada Inc 
partnership with the CCFC, CIHR and industry, is a valuable program to attract students to the field. Efforts have been made to include trainee members on CAG committees. The new CAG governance and policies are designed to allow flexibility in this area to better enable trainees and interested physicians and scientists to participate in the affairs of the organization.

In response to interest from the community and provincial associations, a new research award focused on community gastroenterologists - the Community Research Grant (CREG) - has been instituted in partnership with the CDHF and is now offered in alternate years with the established Clinician Professional Education Grant (CPEG). Fellowships continue to support the training of clinicianscientists; however, there has been no expansion in this area, and no increase in funding to enhance enticement of intensive and longer periods of training. While funding of research for residents, students and new investigators has been stellar over the past few years, the current economic environment will require the organization to creatively find other sources of research funding in the future. Clinical gastroenterology training programs have been reduced in size in some provinces despite the recognized need to train more health care specialists in the field of digestive health and disease. Career opportunities in gastroenterology are available; however, in some regions of the country, there are limitations associated with the availability of endoscopy resources and university funding for academic research positions. Gastroenterology training program directors have effectively promoted and contributed to the development of enhanced standards for the Royal College of Physicians and Surgeons of Canada (RCPSC) training programs.

\section{Principal Initiative 2}

Significant energy and resources have been allocated in an attempt to influence and improve the delivery of digestive health care. In the 2004 strategic plan, this was an area identified to require increased attention and action. The CAG, as an active member of the WTA, has corresponded and interacted with government and the public regarding wait times and access to care. As well, the organization has responded to several regulatory issues such as lobbying the Canadian Drug Review Agency for the use of new and existing drugs for the treatment of digestive diseases. The CAG Research Committee and CAG members from the research community have participated in the CIHR Nutrition, Metabolism and Diabetes Institute forum on the CIHR strategic plan. Despite this activity, limited progress has been made, and the CAG still does not have the attention of the federal or provincial governments, nor does it have a voice with the Canadian public at large. During the past five years, the CAG has taken a greater role in advocating for digestive health care, quality assurance, research and educational resources. Continued growth and success in this area requires the development of enhanced relationships, practice and research information, and collaborative work with our Foundation, provincial associations, partners and affiliated organizations. Working with the CDHF, the CAG has initiated a process to plan for a National Digestive Health Strategy to further address the situation that, hopefully, results in a united voice to government and other agencies. The CAG, in partnership with our Foundation, the CDHF, has been proactive in trying to engage policy and decision makers at all levels.

\section{Principal Initiative 3}

During the past five years, the CAG has worked to promote and enhance professional alliances and provincial partnerships. Positive progress has been made through the provision of educational programs, program accreditation, the visiting professorship program and collaborative wait time assessment initiatives. However, care is largely delivered provincially and, as a national organization, there have been challenges linking to the provincial concerns. Additional opportunities have been identified to help provincial organizations in areas such as Web site and administrative support, assistance with the organization of regional meetings and the opportunity 
for community physicians to obtain research funding to address specific practice-related issues. The CDHF is also an important link to provincial organizations by providing valuable educational materials for patients. There is a need for ongoing activity in this area.

The CAG has also made strides in efforts to impact gastroenterology on a global scale. Assistance has been provided to enable the delivery of equipment to developing nations such as Jamaica, Bolivia, Uruguay and Madagascar. Funds from the very successful 2005 World Congress of Gastroenterology, held in Montreal, Quebec, have established the Legacy Fund Education Grant that will support initiatives to improve training opportunities for individuals from developing countries. In addition, the Latin American Studentship provides the opportunity for trainees from developing countries to be exposed to research opportunities in Canada. The CAG also provides support for international trainees and faculty to attend the GRIT program at CDDW.

\section{Principal Initiative 4}

Supporting and enhancing the scope of clinical practice and educational and research programs have been ongoing priorities of the organization since its inception in 1962. Considerable activity, progress and success in these areas have occurred during the past five years. The CAG is an accredited RCPSC Maintenance of Certification provider and has been recognized for leadership in this area. Maintenance of certification is an important service for the membership. The recently introduced CAG Internet-based educational portal (ePortal, www.cageportal.org) provides an opportunity for further educational activities and increased opportunities for practice audit, selfevaluation and personal learning projects. An Internet-based quality assurance program (10), building on the PAGE practice audit programs, related to the practice of colonoscopy has been established and allows point-of-care assessment for our members, with the ability of real-time comparison of personal performance with peers. The CAG has received strong support from the RCPSC with regard to the practice audit program because it directly fulfills the College's mandates to provide more mechanisms for self-assessment and excellent methods to identify unperceived needs

The interactive lecture series has been remodelled to provide more access to live lecture recordings. To enhance the access and longevity of excellent educational material from CDDW and regional meetings, the CAG has invested in technology that records lectures and programs, and allows for their distribution on the ePortal in multiple formats including videos and podcasts.

Highly rated trainee educational events, including national noon hour basic science video conferencing rounds, and the GRIT and Scholars programs at CDDW, have continued to develop. They provide a forum for trainees to be exposed to the specialty, attend high-quality interactive courses and engage with physicians, scientists and peers from across the country.

CDDW continues to advance, and is recognized to be a high-quality educational forum that is guided by annual polling of the members' educational needs through formal needs assessment. It is recognized as a meeting of choice for practicing gastroenterologists in Canada.
The Canadian Journal of Gastroenterology has grown and evolved into a clinical journal that is very supportive of Canadian clinical research. The steady increase in impact factor over the past five years is a testament to the dedication and commitment of the Editorial Board.

Limited support is provided by the CAG for locally organized regional meetings. However, there are no regional clinical or research meetings that are organized by the CAG. This has been identified as a deficiency by the membership. Steps are being taken to work with provincial organizations to provide regional meetings to further support the gastroenterology community.

The CAG has sponsored the creation and dissemination of a number of clinical practice guidelines $(5,11-14)$ over the past several years that have been well received and have influenced digestive health care.

The development of the CDHF as a research fund-raising vehicle has tremendous potential for CAG members.

Awards have been established to acknowledge and promote excellence in the clinical, education and research areas. Young educator, education excellence, young investigator, research excellence and visiting professor awards recognize success, and help raise the profile of digestive disease care and science across the country.

There is an ongoing need to develop and use computerbased technologies to assist research endeavours, including clinical trials and databases for quality assurance projects.

\section{Principal Initiative 5}

In 2009, the CAG completed a comprehensive review of the organizational structure resulting in updated bylaws that are now supported by governance policies. The new model is the foundation to grow resources to provide additional and enhanced services to members of the CAG. The CAG is guided by and adheres to the Canadian Medical Association code of ethics, and has developed principles and guidelines for interaction with industry. During the past five years, sponsorships and partnerships with industry have been expanded; however, this trend is unlikely to continue. Audited annual statements confirm that the organization is in a sound financial situation, with reserves sufficient to operate the CAG office for one year and to support one annual meeting (CDDW).

The revitalization and restructuring of the CDHF has been a significant step forward in achieving secured endowments to support research and training awards. In addition to raising the profile and public awareness of digestive health and disease, the Foundation has significant potential to raise funds to support national research and public education programs. Recent activities have focused on developing a National Digestive Health Strategy to increase awareness of digestive health and disease, and to secure new funding resources. Important steps have been taken; however, considerable work remains to be completed.

\section{SUMMARY}

Significant gains have been achieved by the CAG during the past five years. The CAG remains dedicated to professional education, research and patient care in all areas of digestive health and disease in support of the economic and social health of all Canadians. All of the goals and targets associated with the five principal initiatives of the 2004 strategic plan 
have been addressed, and most have been fully or partially achieved. The organization is active on many fronts by engaging partners, strengthening existing programs, addressing areas where goals and targets have not been achieved and creating new initiatives. The focus of these activities is to provide value to you, the member, by improving digestive health and disease

\section{REFERENCES}

1. Sherman PM, Fedorak RN, Leddin D, Wallace JL. Canadian Association of Gastroenterology 2004 Strategic Plan. Can J Gastroenterol 2004;18:125-6.

2. Fedorak R, Sherman P. The 1993

Canadian Association of

Gastroenterology Strategic Plan:

Excellence in achievement.

Can J Gastroenterol 2003;17:683-4.

3. Moayyedi P, Tepper J, Hilsden R, Rabeneck L. International comparisons of manpower in gastroenterology. Am J Gastroenterol 2007;102:478-81.

4. Hilsden RJ, Tepper J, Moayyedi P, Rabeneck L. Who provides gastrointestinal endoscopy in Canada? Can J Gastroenterol 2007;21:843-6.

5. Paterson WG, Depew WT, Pare P, et al; for the Canadian Association of Gastroenterology Wait Time Consensus Group. Canadian consensus on medically acceptable wait times for digestive health care. Can J Gastroenterol 2006;20:411-23.

6. Armstrong D, Hollingworth R, Gardiner T, et al. Practice Audit in Gastroenterology (PAGE) Program: A novel approach to continuing professional development. Can J Gastroenterol 2006;20:405-10.

7. Leddin D, Armstrong D, Barkun AN, et al. Access to specialist gastrenterology care in Canada: Comparison of wait times and consensus targets. Can J Gastroenterol 2008;22:161-7.

8. Armstrong D, Barkun AN, Chen Y, et al. Access to specialist gastroenterology programs. We believe the CAG is well positioned to meet the opportunities and challenges in the years to come. To this end, a new five-year strategic plan is in development and will be presented to the membership in the near future. The CAG leadership welcomes your comments and suggestions to enhance the ongoing development and operation of the organization.

care in Canada: The Practice Audit in Gastroenterology (PAGE) wait times program. Can J Gastroenterol 2008;22:155-60.

9. Leddin D, Bridges RJ, Morgan DG, et al. Survey of Access to

GastroEnterology in Canada:

The SAGE wait times program. Can J Gastroenterol 2010;24:20-5.

10. Hollingworth R, Dube C. The Canadian Association of Gastroenterology Endoscopy Quality Initiative: Leading the wave. Can J Gastroenterol 2009;23:506-9.

11. Armstrong D, Marshall JK, Chiba N, et al. Canadian Consensus Conference on the management of gastroesophageal reflux disease in adults - update 2004. Can J Gastroenterol 2005;19:15-35.

12. Rostom A, Moayyedi P, Hunt R. Canadian consensus guidelines on longterm nonsteroidal anti-inflammatory drug therapy and the need for gastroprotection: Benefits versus risks. Aliment Pharmacol Ther 2009;29:481-96.

13. Sadowski DC, Bernstein CN, Bitton A, et al. Canadian Association of Gastroenterology Clinical Practice Guidelines: The use of tumour necrosis factor-alpha antagonist therapy in Crohn's Disease. Can J Gastroenterol 2009;23:185-202.

14. Barkun AN, Bardou M, Kuipers EJ, et al. International consensus recommendations on the management of patients with nonvariceal upper gastrointestinal bleeding. Ann Int Med 2010;152:101-13. 


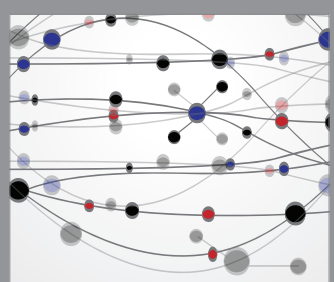

The Scientific World Journal
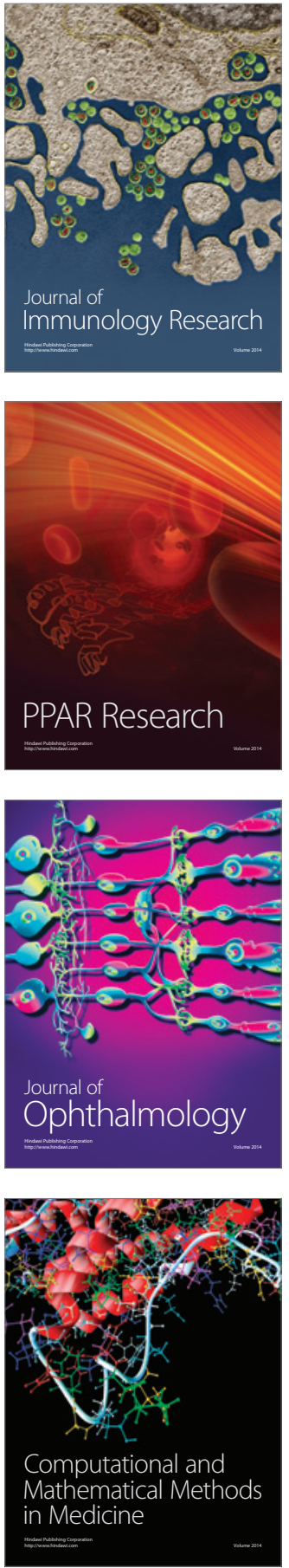

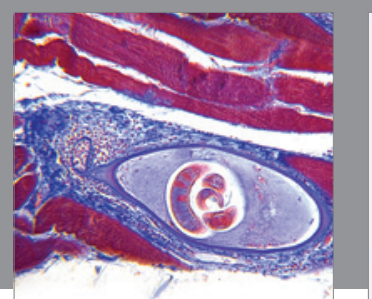

Gastroenterology Research and Practice

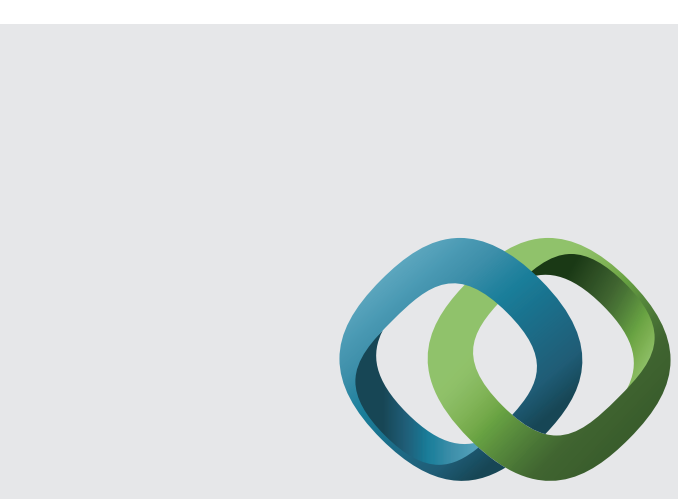

\section{Hindawi}

Submit your manuscripts at

http://www.hindawi.com
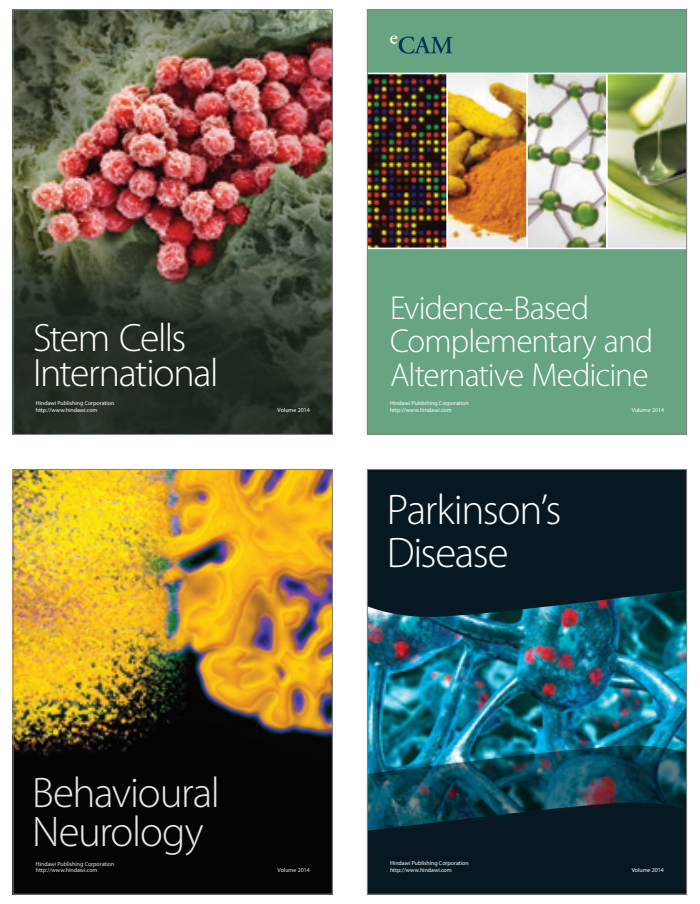
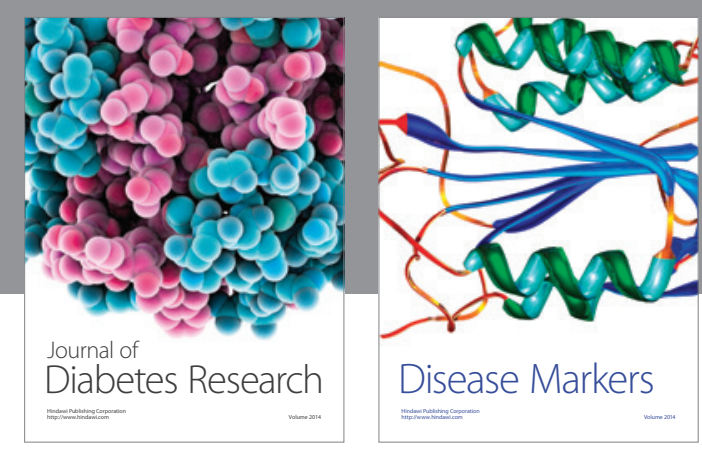

Disease Markers
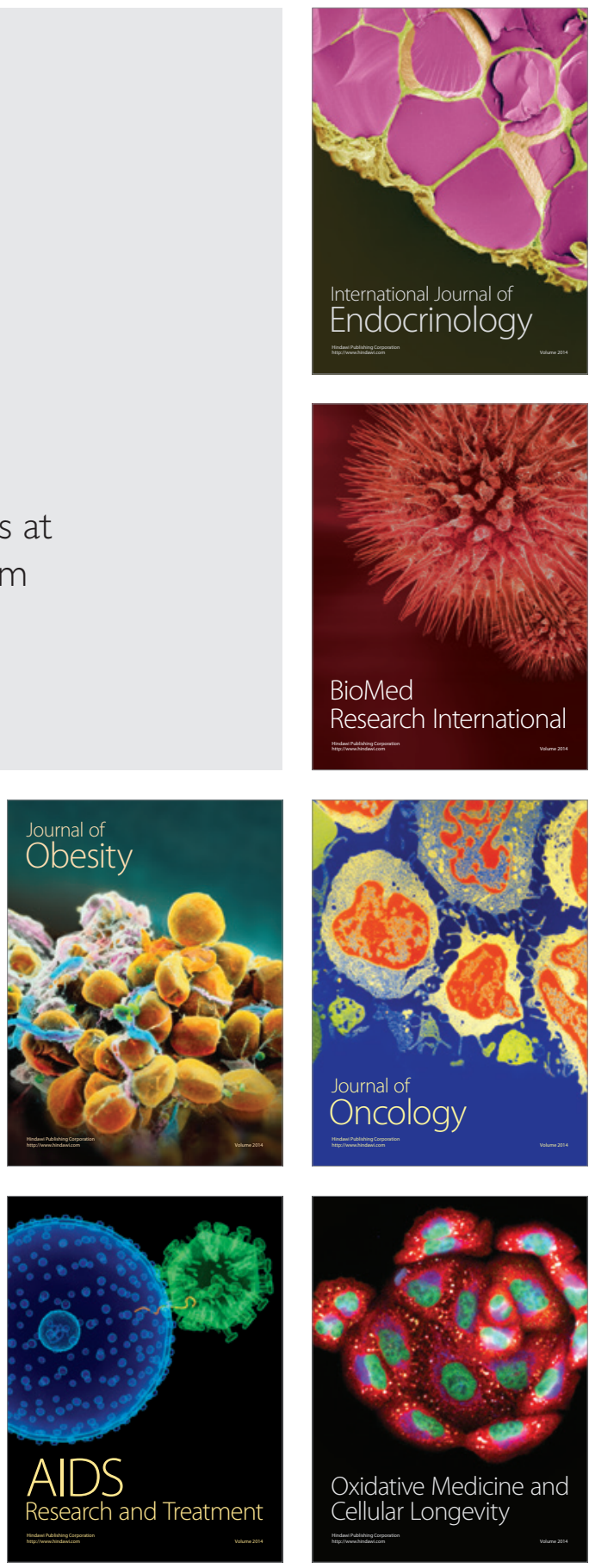